\title{
Virulence and Differential Local and Systemic Spread of Cucumber mosaic virus in Tobacco are Affected by the CMV 2b Protein
}

\author{
Avril J. Soards, ${ }^{1}$ Alex M. Murphy, ${ }^{1}$ Peter Palukaitis, ${ }^{2}$ and John P. Carr ${ }^{1}$ \\ ${ }^{1}$ Department of Plant Sciences, University of Cambridge, Cambridge CB2 3EA, U.K.; ${ }^{2}$ Virology Unit, Scottish Crop \\ Research Institute, Invergowrie, Dundee DD2 5DA, U.K.
}

Submitted 10 September 2001. Accepted 22 February 2002.

\begin{abstract}
A mutant of the Cucumber mosaic virus subgroup IA strain Fny (Fny-CMV) lacking the gene encoding the $2 \mathrm{~b}$ protein (Fny-CMV $\Delta 2 b)$ induced a symptomless systemic infection in tobacco. Both the accumulation of Fny-CMV $\Delta 2 \mathrm{~b}$ in inoculated tissue and the systemic movement of the virus appeared to proceed more slowly than for wild-type Fny-CMV. The influence of the $2 \mathrm{~b}$ protein on virus movement in the inoculated leaf was examined using viral constructs derived from Fny-CMV and Fny-CMV $\Delta 2$ b expressing the green fluorescent protein. Laser scanning confocal microscopy was used to visualize the movement of these viruses. Whereas the wildtype virus spread between the epidermal cells as well as the mesophyll cells, the mutant virus spread less efficiently through the epidermal layer and moved preferentially through the mesophyll. Thus, the $2 \mathrm{~b}$ protein of Fny-CMV influences the dynamics of movement of the virus both within the inoculated leaf and through the whole plant. We propose that this altered movement profile of Fny-CMV $\Delta 2 \mathrm{~b}$ results in the absence of disease symptoms in tobacco.
\end{abstract}

The severity of the disease caused by a plant virus depends upon, among other things, the ability of the virus to move locally and systemically, perturb tissue or organ development (i.e., induce disease symptoms), and to evade the host's defensive mechanisms. Certain viruses encode multifunctional proteins that control or influence all of these factors. The most notable examples of such multifunctional viral proteins are the potyviral $\mathrm{HC}$-Pro protein and the $2 \mathrm{~b}$ protein encoded by $\mathrm{Cu}$ cumber mosaic virus (CMV) and related viruses (Kasschau and Carrington 2001; Li and Ding 2001).

CMV, Tomato aspermy virus (TAV), and Peanut stunt virus constitute the major species in the genus Cucumovirus, a group of tripartite, positive strand, RNA viruses (Adams et al. 1998). Based on RNA sequence data, CMV is further classified into three subgroups, IA, IB, and II (Roossinck et al. 1999). Until recently, only four CMV-encoded proteins were known to occur in virus-infected host cells. The $1 \mathrm{a}$ and $2 \mathrm{a}$ proteins are translated directly from genomic RNAs 1 and 2, respectively, and are involved in virus replication. Similarly, the 3a movement protein (MP) is translated directly from genomic RNA 3, while the coat protein $(\mathrm{CP})$, which is encoded by the $3^{\prime}$-proximal open reading frame (ORF) of RNA 3, is translated from a subgenomic RNA, RNA 4 (Palukaitis et al. 1992). Although it had been known since the 1970s that an additional subgenomic RNA, RNA 4A,

Corresponding author: John P. Carr; Fax +44 1223 333953; E-mail jpc1005@hermes.cam.ac.uk. was synthesized during viral replication (Peden and Symons 1973), it was not until relatively recently that RNA 4A was conclusively shown to be active as a mRNA in planta (Ding et al. 1994). RNA 4A is the template for a fifth viral protein, the $2 b$ protein, which is encoded by a 3 '-proximal ORF from the RNA 2 of both CMV and TAV (Ding et al. 1994).

Deletion of the $2 \mathrm{~b}$ protein from the subgroup II virus, Q-CMV, yielded a mutant virus (Q-CMV $\Delta 2 \mathrm{~b}$ ) that was less virulent than the wild-type virus. Q-CMV $\Delta 2 \mathrm{~b}$ was unable to systemically infect cucumber (Cucumis sativus) plants but could systemically infect Nicotiana glutinosa (Ding et al. 1995b). A chimeric virus in which the $2 \mathrm{~b}$ protein of Q-CMV was replaced by the TAV $2 b$ protein showed increased virulence (increased severity of symptoms and increased viral RNA accumulation) on seven different host species (Ding et al. 1996). These findings led to the initial conclusion that the cucumoviral $2 \mathrm{~b}$ protein functioned in the control of systemic virus movement and symptom expression (Ding et al. 1995b, 1995c, 1996). It is now clear that, at least in part, the cucumoviral $2 \mathrm{~b}$ protein also exerts effects on the functioning of two antiviral defense mechanisms. Specifically, the $2 \mathrm{~b}$ protein can suppress the initiation of RNA silencing (Béclin et al. 1998; Brigneti et al. 1998) and salicylic acid-induced resistance (Ji and Ding 2001). It is not clear how the $2 \mathrm{~b}$ protein acts as a counterdefense factor. However, two recent studies have indicated that the $2 \mathrm{~b}$ protein localizes to the host cell nucleus (Lucy et al. 2000; Mayers et al. 2000). This nuclear localization appears to be essential for suppression of RNA silencing (Lucy et al. 2000), and it is reasonable to suppose that the $2 \mathrm{~b}$ protein is acting by suppressing the expression of host defense genes.

So far, the majority of work on the biological properties of the $2 \mathrm{~b}$ protein has used either the subgroup II CMV strain Q-CMV or TAV (Li and Ding 2001). However, subgroup II strains of CMV are much less virulent on tobacco than subgroup I strains (Palukaitis et al. 1992; Zhang et al. 1994), so it is of interest to see how the biological properties of the subgroup I and II $2 \mathrm{~b}$ proteins compare. In this study, we investigated whether the $2 \mathrm{~b}$ protein of a subgroup IA CMV strain could influence systemic movement or symptom severity, or both, in tobacco. In addition, we used genetically modified CMV constructs expressing free green fluorescent protein (GFP) to assess the effects of the $2 b$ protein on virus movement within the inoculated leaf.

\section{RESULTS}

Systemic infection with Fny-CMV $\Delta 2 \mathrm{~b}$ is symptomless on tobacco.

Tobacco plants were inoculated with wild-type Fny-CMV and Fny-CMV $\triangle 2 b$ using RNA transcribed in vitro from the 
DNA constructs detailed in Table 1. At 8 days postinoculation (dpi), proteins were extracted from inoculated and upper, uninoculated leaves of plants inoculated with Fny-CMV and Fny-CMV $\Delta 2$ b. The extracted proteins were analyzed by protein immunoblotting using anti-CP serum to ascertain if FnyCMV $\Delta 2 b$ was capable of replicating and moving systemically (Fig. 1, upper panel). During extraction, the CMV CP is subject to breakdown, which is responsible for the appearance of multiple cross-reacting bands in some of the protein extracts in the upper panel. It was found that both wild-type Fny-CMV and Fny-CMV $\Delta 2 \mathrm{~b}$ can replicate successfully in inoculated leaves of tobacco and are capable of systemic movement (Fig. 1, upper panel). The lower level of $\mathrm{CP}$ accumulation in leaves infected systemically by Fny-CMV $\Delta 2 \mathrm{~b}$ was observed consistently in several experiments.

Proteins extracted from the same plants were also analyzed using anti-2b serum (Fig. 1, lower panel). The analysis showed that the $2 \mathrm{~b}$ protein was present in wild-type FnyCMV-infected plants but absent from Fny-CMV $\Delta 2$ b-infected plants. These results demonstrate that the $2 \mathrm{~b}$ protein is not required for successful systemic movement of Fny-CMV in tobacco.

Typical CMV disease symptoms were observed on the upper leaves of tobacco plants infected with wild-type Fny-CMV (Fig. 2). In stark contrast, the upper leaves of plants inoculated with Fny-CMV $\Delta 2$ b did not develop disease symptoms and were identical in appearance to the leaves of mock-inoculated tobacco, even at $14 \mathrm{dpi}$ (Fig. 2). The data indicates that the $2 \mathrm{~b}$

Table 1. Constitution of RNA inocula for Fny-CMV wild type and derivatives.

\begin{tabular}{|c|c|c|}
\hline Virus Construct & $\begin{array}{c}\text { Transcription } \\
\text { Templates }\end{array}$ & Reference \\
\hline \multirow[t]{3}{*}{ Fny-CMV } & pFny109 & Rizzo and Palukaitis 1989 \\
\hline & pFny209 & Rizzo and Palukaitis 1988 \\
\hline & pFny309 & Owen and Palukaitis 1988 \\
\hline \multirow{2}{*}{ Fny-CMV $\Delta 2 b$} & pFny 109 & \\
\hline & $\begin{array}{l}\text { pFny } 209 / \mathrm{M} 3 \\
\text { pFny309 }\end{array}$ & Ryabov et al. 2001 \\
\hline \multirow[t]{3}{*}{ CMV-GFP } & $\begin{array}{l}\text { pFny109 } \\
\text { pFny209 }\end{array}$ & \\
\hline & pF:GFP/CP & Canto et al. 1997 \\
\hline & pL:3a/GFP & Canto et al. 1997 \\
\hline \multirow{4}{*}{$\mathrm{CMV} \triangle 2 \mathrm{~b}-\mathrm{GFP}$} & pFny 109 & \\
\hline & pFny209/M3 & \\
\hline & $\mathrm{pF}: \mathrm{GFP} / \mathrm{CP}$ & \\
\hline & $\mathrm{pL}: 3 \mathrm{a} / \mathrm{GFP}$ & \\
\hline
\end{tabular}

protein of the subgroup IA strain Fny-CMV influences symptom development, as was also found for subgroup II strain QCMV (Ding et al. 1996).

\section{The accumulation and systemic movement of Fny-CMV $\Delta 2 \mathrm{~b}$ appears to proceed more slowly than for wild-type Fny-CMV.}

The $2 \mathrm{~b}$ protein of Fny-CMV appears to function as a symptom determinant, either directly or indirectly. However, the lack of disease symptoms exhibited in Fny-CMV $\Delta 2$ b-infected tobacco could be explained by the decreased rate of virus accumulation and systemic movement compared with wild-type Fny-CMV rather than being due to the $2 b$ protein directly evoking a host response. To investigate this possibility, time course experiments were conducted in which groups of tobacco plants of the same age (6 weeks postgermination) were inoculated with either Fny-CMV or Fny-CMV $\Delta 2$ b. To detect virus accumulation, proteins were extracted from inoculated and upper, uninoculated leaves of the plants at two time points after inoculation and subjected to immunoblot analysis using antiCP serum. Wild-type Fny-CMV had already accumulated to detectable levels in both inoculated and systemic leaves by 6 dpi (Fig. 3, plants 1 and 2). In contrast, Fny-CMV $\Delta 2$ b was only detectable in the inoculated leaves at $6 \mathrm{dpi}$ (Fig. 3, plants 3 and 4). But, by 8 dpi, Fny-CMV $\Delta 2$ b accumulation was apparent in upper, uninoculated leaves as well as in the inoculated leaves (Fig. 3, plants 7 and 8 in lower panel); however, less CP was detected than in the upper leaves of plants infected with wild-type Fny-CMV (Fig. 3, U lanes in lower panel). Thus, it appears that the Fny-CMV $\Delta 2 \mathrm{~b}$ mutant virus is less able than the wild-type virus to spread systemically and that it accumulates to lower levels than wild type in inoculated and upper, uninoculated tissues. Either, or both, of these effects may be responsible for the inhibition of disease symptom development, although the possibility that the Fny-CMV 2 b protein directly influences symptoms cannot be excluded.

\section{Fny-CMV $\Delta$ 2b spreads preferentially through the mesophyll tissue in the inoculated leaves.}

To investigate whether the $2 \mathrm{~b}$ protein of Fny-CMV influences local spread of CMV, in addition to its effects on systemic movement, confocal scanning laser microscopy was used to track the distribution of GFP-expressing CMV constructs that did or did not contain the Fny-CMV 2 b gene (Table 1). Optical sectioning through infection sites in directly inoculated leaves revealed that the distribution of CMV $\Delta 2 \mathrm{~b}-\mathrm{GFP}$ within

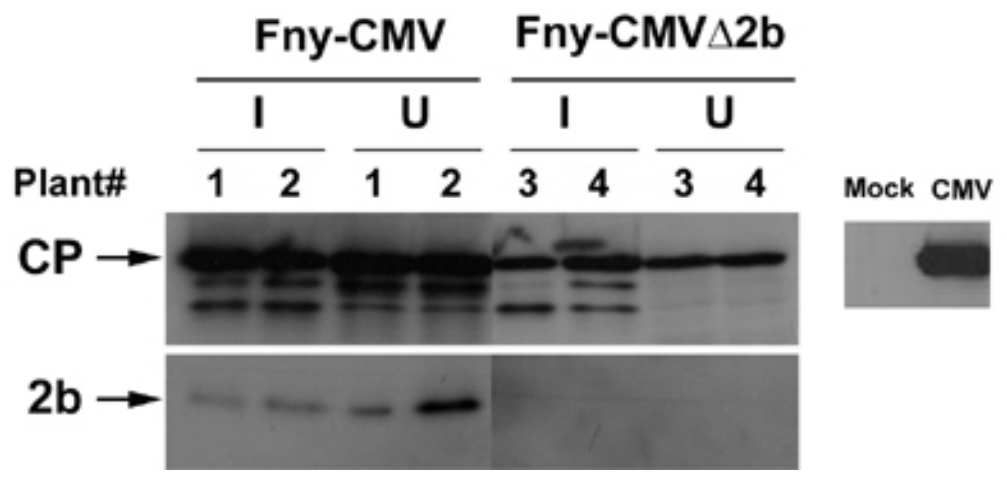

Fig. 1. Accumulation of the Cucumber mosaic virus subgroup IA strain Fny (Fny-CMV) coat protein (CP) and $2 \mathrm{~b}$ protein in inoculated and systemically infected leaves of tobacco. Tobacco plants were inoculated with Fny-CMV (plants 1 and 2) or with Fny-CMV $\Delta 2$ b (plants 3 and 4 ), and at 8 days postinoculation, proteins were extracted from the inoculated (I) and upper, uninoculated (U) leaves. Equal quantities of protein were subjected to sodium dodecyl sulfate-polyacrylamide gel electrophoresis and immunoblotted using anti-CP (upper panel) or anti-2b serum (lower panel). The position of $\mathrm{CP}$ (apparent $\mathrm{M}_{\mathrm{r}} 24 \mathrm{kDa}$ ) and the $2 \mathrm{~b}$ protein (apparent $\mathrm{M}_{\mathrm{r}} 17 \mathrm{kDa}$ ) are indicated (prestained marker proteins transferred to the blot were used to estimate the $\mathrm{M}_{\mathrm{r}}$ of cross-reacting proteins but were not visible on the $\mathrm{X}$-ray film). Lanes containing protein from a mock-inoculated (Mock) plant and purified virus (CMV) probed with anti-CP serum are shown for comparison. Some extracts contained breakdown products of the $\mathrm{CP}$ that cross-reacted with the anti-CP serum. 
tobacco leaf tissue differed from that of CMV-GFP (Fig. 4). At $4 \mathrm{dpi}, \mathrm{CMV}-\mathrm{GFP}$ had spread extensively through the epidermal cell layer (Fig. 4A, panels 1 and 2). Optical sectioning through infection sites revealed that CMV-GFP had also moved into the palisade mesophyll cells, (Fig. 4A, panels 3 and 4). However, at this time point, proportionately more palisade mesophyll cells relative to epidermal cells displayed GFP fluorescence in CMV $\triangle 2$ b-GFP inoculated tissue than in tissue inoculated with CMV-GFP (Table 2).

In clear contrast to the movement profile of CMV-GFP, CMV $\triangle 2 \mathrm{~b}$-GFP showed only very limited movement through the epidermal cell layer (Fig. 4B, panel 1) but extensive movement through the palisade mesophyll cells (Fig. 4B panels 2, 3, and 4). Thus, the cell-to-cell movement of CMV 2 2b-GFP between epidermal cells is severely restricted, but its movement through the palisade cell layer appears to be enhanced compared with the movement of CMVGFP in this cell type (Fig. 4C). In summary, although the overall diameter of CMV-GFP and CMV $\triangle 2 \mathrm{~b}-\mathrm{GFP}$ infection sites are similar, the ratio of infected epidermal cells to infected mesophyll cells is quite different. This suggests that the $2 \mathrm{~b}$ protein plays a tissue- or cell-specific role in cell-tocell movement of CMV.

\section{The replication of CMV-GFP and CMV $\triangle 2 \mathrm{~b}-\mathrm{GFP}$ in protoplasts.}

Protoplast experiments were carried out in an attempt to determine whether the alteration in the pattern of virus movement seen with CMV $\triangle 2 \mathrm{~b}$-GFP could be attributed to an effect on viral replication. Protoplasts were electroporated with transcripts constituting either CMV-GFP or CMV $\triangle 2$ b-GFP (Table 1). The inoculated protoplasts were monitored using a confocal laser scanning microscope for the first appearance of GFP fluorescence as an indicator for the replication of the two viral constructs. In three separate experiments, GFP fluorescence was seen first in the protoplasts inoculated with CMV-GFP $(16 \mathrm{~h}$ postelectroporation) followed, consistently, $1.5 \mathrm{~h}$ later by the appearance of GFP fluorescence in the protoplasts inoculated with CMV $\triangle 2 \mathrm{~b}$-GFP (data not shown). These observations show that replication of CMV $\triangle 2 \mathrm{~b}-\mathrm{GFP}$ is slower, at least initially, than replication of CMV-GFP. However, by $20 \mathrm{~h}$ postelectroporation both constructs appeared to reach similar levels in infected protoplasts. In two of the experiments, the GFP fluorescence in protoplasts infected with CMV-GFP or CMV 2 b-GFP was measured at this time point (Fig. 5). In both experiments the difference between the two sets of inte-

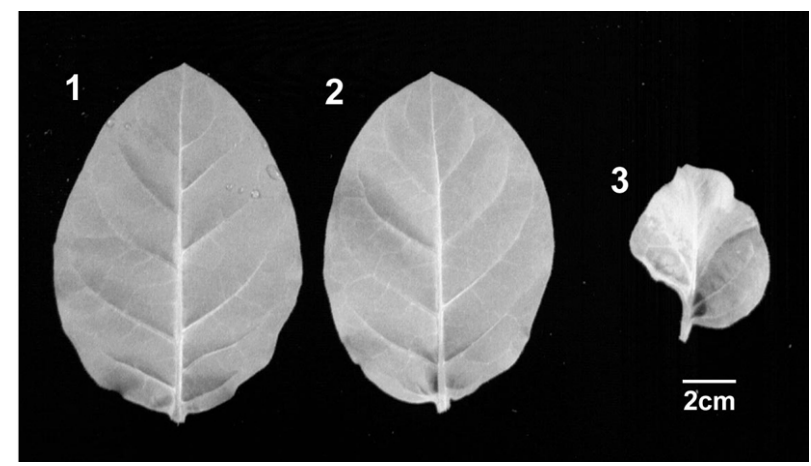

Fig. 2. Systemic disease symptoms in tobacco infected with Cucumber mosaic virus subgroup IA strain Fny (Fny-CMV) and with Fny-CMV with the $2 \mathrm{~b}$ protein open reading frame deleted (Fny-CMV $\Delta 2 \mathrm{~b}$ ). The photograph shows the appearance of uninoculated upper leaves from a mock-inoculated plant (1), a plant inoculated with Fny-CMV $\Delta 2 \mathrm{~b}(2)$, and a plant inoculated with wild-type Fny-CMV (3) at 14 days postinoculation. grated values was also tested for using the Student $t$ test (data not shown). There was no significant difference between the levels of GFP fluorescence in the two sets of protoplasts, indicating that both CMV-GFP and CMV $\triangle 2 \mathrm{~b}-\mathrm{GFP}$ were able to replicate to similar levels. The experiments suggest that, although the deletion of the $2 b$ protein gene sequence did slightly affect the rate of replication of CMV, it did not prevent the deletion mutant from reaching the same level as the virus expressing the $2 \mathrm{~b}$ protein.

\section{DISCUSSION}

Our results show that the $2 \mathrm{~b}$ protein of a subgroup IA strain of CMV acts as a symptom determinant in tobacco. This is broadly consistent with results obtained for Q-CMV, a subgroup II strain of CMV (Ding et al. 1995b; Ji and Ding 2001). In young $N$. glutinosa plants, Q-CMV $\Delta 2 \mathrm{~b}$ moved systemically but remained asymptomatic (Ji and Ding 2001). Our results indicate that the lack of disease symptoms exhibited in FnyCMV $\Delta 2$ b-infected tobacco plants may be due to a decrease in the ability of the virus to move systemically and to accumulate to levels required at a critical time in those tissues for the onset of symptom development. Furthermore, our results show clearly that the $2 \mathrm{~b}$ protein appears to play a tissue- or cell-specific role in local CMV movement.

Two thirds of ORF $2 b$ overlaps ORF 2a. Consequently, the $2 \mathrm{~b}$ deletion mutant of RNA 2 (encoded by pFny209/M3; Table 1) encodes a truncated 2 a protein. We addressed the possibility that the deletion of the $2 b$ gene, the consequent truncation of the ORF for the 2 a protein, or both might affect replication. Using protoplasts, it was found that the accumulation of the deletion mutant to detectable levels was slightly delayed, although this construct could still reach the same level of accumulation as CMV possessing the wild-type RNA 2 sequence. Thus, deletion of part of RNA 2 did affect the replication characteristics of the virus. However, it remains unclear whether this was due to deletion of the $2 b$ ORF or to truncation of the $2 \mathrm{a}$ protein. In any case, the effect on replication in protoplasts was small and, therefore, this effect is unlikely to explain entirely the altered pattern of virus distribution in intact tissue infected with CMV $\triangle 2 \mathrm{~b}$-GFP. Moreover, the greater proportion of the protoplasts prepared using our method are derived from mesophyll cells. In Figure 4 and Table 2, it can be seen that CMV $\Delta 2$ b-GFP proliferates quite effectively in this cell type.

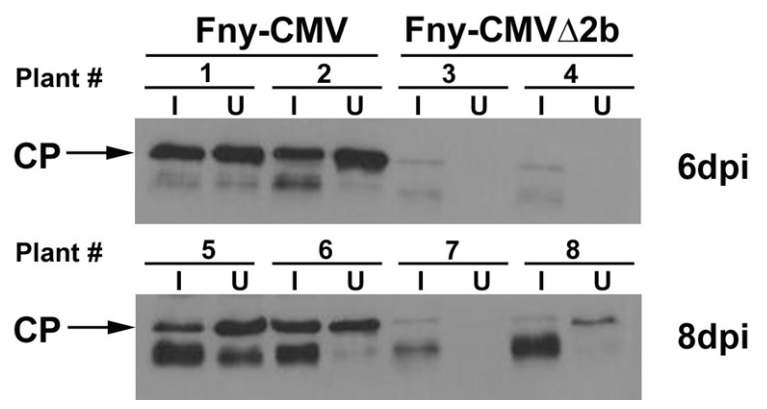

Fig. 3. The accumulation of Cucumber mosaic virus subgroup IA strain Fny (Fny-CMV) with the $2 \mathrm{~b}$ protein open reading frame deleted (FnyCMV $\Delta 2 \mathrm{~b}$ ) is slower than that of wild-type Fny-CMV in inoculated and systemically infected tobacco leaves. Tobacco plants were inoculated with Fny-CMV (Plants 1, 2, 5, and 6) or Fny-CMV $\Delta 2$ b (plants 3, 4, 7, and 8). After 6 (upper panel, plants 1 to 4 ) or 8 days (lower panel, plants 5 to 8 ), proteins were extracted from the directly inoculated (I) or upper uninoculated $(\mathrm{U})$ leaves of the plants. Equal amounts of protein were analyzed by sodium dodecyl sulfate-polyacrylamide gel electrophoresis and immunoblotting using anti-CP serum. The position of the Fny-CMV $\mathrm{CP}$ is indicated. Some extracts contained breakdown products of the $\mathrm{CP}$ that cross-reacted with the anti-CP serum. 
This further supports the idea that inhibition of replication (at least in the mesophyll cells) is not directly responsible for the altered distribution of CMV $\Delta 2 \mathrm{~b}-\mathrm{GFP}$.

There are, in addition, other reasons why it is most probable that the effects on movement and symptom development discussed in this report were due to the deletion of the $2 b$ protein rather than the truncation of the $2 \mathrm{a}$ protein. For example, Ding and associates (1995b) showed that for Q-CMV, the $3^{\prime}$ end of ORF $2 a$, the coding sequence which overlaps that of ORF $2 b$, is dispensable for efficient virus infection and, by implication, for viral replication as well. Sequence comparisons also support this conclusion, because subgroup IA and subgroup II strains of CMV differ considerably in this region and the lack of conservation suggests that this region is not essential for replication. Moreover, the V strain of TAV has an RNA 2 that encodes a $\mathrm{C}$-terminally truncated $2 \mathrm{a}$ protein, and the TAV ORF $2 \mathrm{a}$ overlaps to a lesser extent with the $2 \mathrm{~b}$ ORF than in CMV strains (Ding et al. 1995b). This issue could not be addressed directly for Fny-CMV, since introduction of a termination codon in the 2a ORF immediately upstream of the $2 \mathrm{~b}$ ORF proved to be unstable and, upon passage of this modified CMV, it reverted to wild-type Fny-CMV (data not shown).

CMV has a very wide host range (Palukaitis et al. 1992). The ability of CMV to move from the primary inoculated cell out radially through epidermal tissue before moving down into deeper cell layers may be essential for the colonization of the host by the virus in certain plants. Functional studies on molecular transport through plasmodesmata of different cell types have shown differences in their basal size exclusion limits and their response to virus movement protein (Waigmann and Zambryski 1995). As these ultrastructural differences exist between the plasmodesmata of different cell types, the $2 \mathrm{~b}$ protein may aid viral transport through certain types of plasmodesmata. This effect may be direct, by preventing the formation of host barriers restricting movement between certain cell types, or by overcoming the effects of such barriers. It has been ob-

\section{A. CMV-GFP}
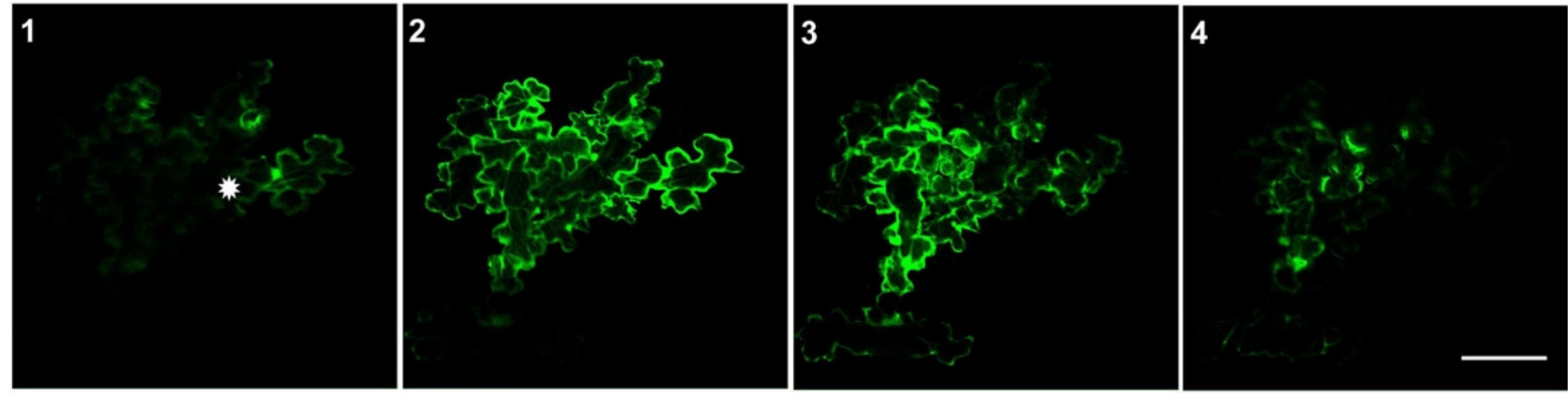

\section{B. $\mathrm{CMV} \Delta 2 \mathrm{~b}$-GFP}
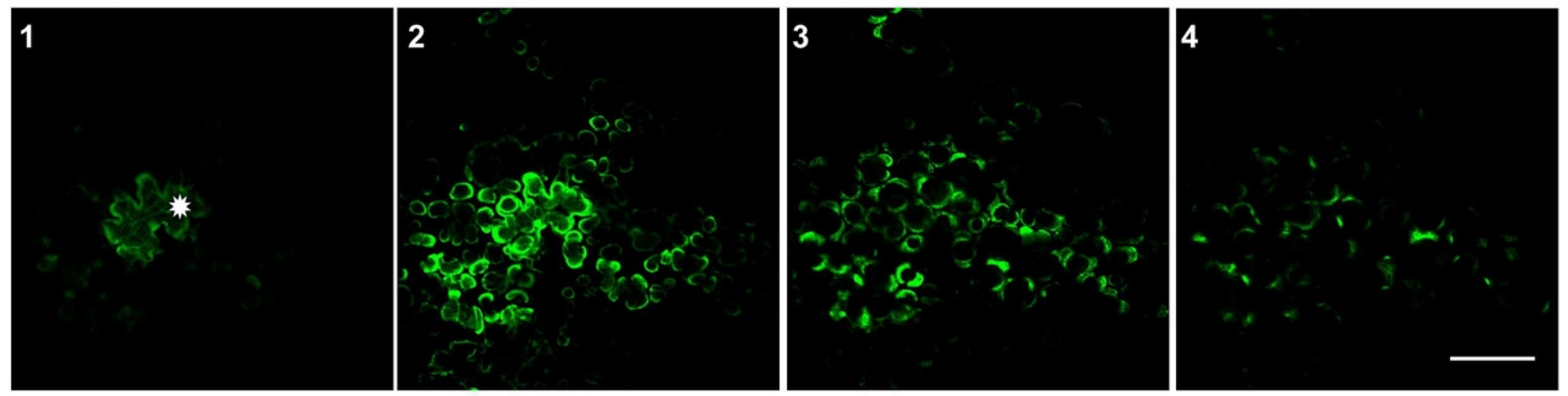

\section{C. $C M V \Delta 2 b-G F P$}

\section{CMV-GFP}
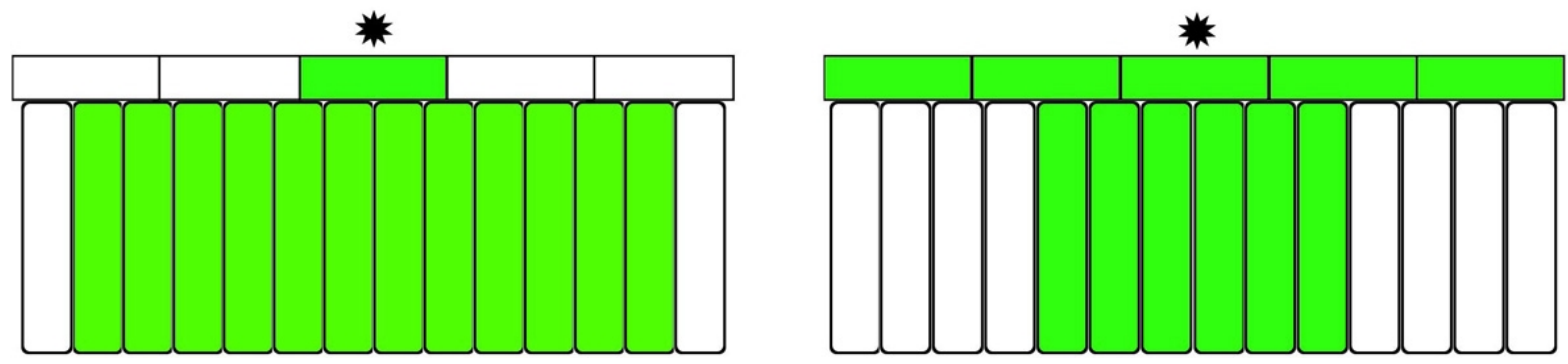

Fig. 4. Confocal scanning laser microscopy of infection sites of Cucumber mosaic virus (CMV) expressing the green fluorescent protein (CMV-GFP) and CMV expressing GFP with the $2 \mathrm{~b}$ protein open reading frame deleted (CMV $\Delta 2 \mathrm{~b}-\mathrm{GFP})$. Shown are representative inoculation sites 4 days after inoculation with A, CMV-GFP or B, CMV $\triangle 2 \mathrm{~b}$-GFP. Images 1 to 4 represent optical sections moving down into the leaf from the epidermal cells at the leaf surface (1) to the underlying palisade mesophyll cells (4). The scale bar represents $100 \mu \mathrm{m}$. C, A schematic diagram of the results shown in A and B. The diagram represents a transverse section through part of a leaf with epidermal cells at the top of the diagram and palisade mesophyll cells underneath. The green shading represents the cells within the leaf tissue that fluoresce due to GFP-tagged virus infection. Primary virus-inoculated epidermal cells are indicated by an asterisk (*). 
served in at least one study that the numbers of plasmodesmata between cells can be altered by virus infection. Shalla and associates (1982) noted that the average number of plasmodesmata in the cell walls between the mesophyll cells of tobacco infected with the LS1 strain of Tomato mosaic virus decreased at a temperature that did not permit movement of the virus. Those results imply that a possible host response to virus infection may be the breakdown of plasmodesmata and that certain viruses may have the ability to counter this process. Conceivably, the CMV $2 b$ protein may perform such a role in the epidermal cell layer. Alternatively, the effect may be indirect, by inhibiting host RNA-silencing resistance responses that could target the CMV RNAs for destruction (Carrington 1999).

The two viral proteins that are known to be required for cellto-cell movement of CMV are the MP and the CP (Canto et al. 1997). It is known that the CMV MP localizes to plasmodesmata, where it modifies the gating capacity of plasmodesmata linking both mesophyll and epidermal cells. In addition, it can traffic itself and viral RNA through the plasmodesmata (Canto et al. 1997; Ding et al. 1995a). The CMV MP can also form tubular structures when expressed in protoplasts. However, this property of the MP is not absolutely required for the spread of CMV (Canto and Palukaitis 1999). One particular mutation of the MP that eliminated the ability of CMV MP to form tubules in protoplasts also affected the ability of CMV to spread between tobacco epidermal cells but not the ability of CMV to spread to, between, or from mesophyll cells (Canto and Palukaitis 1999). Since, in this study, deletion of the $2 b$ protein from CMV inhibited (but did not abolish) movement through the epidermal cells, this may imply some coordination of function between the $2 \mathrm{~b}$ protein and the MP in controlling virus spread in the epidermal cell layer.

The situation described here is not the only similarity in phenotype between a mutation in the CMV MP and the $2 \mathrm{~b}$ protein. Similar differences from wild-type CMV, in both the pathology and the kinetics of virus accumulation in inoculated and systemic leaves, to those described here for a deletion of the $2 b$ gene were observed for another MP mutant of Fny-CMV (Kaplan et al. 1995). In that case, Fny-CMV with a deletion of the MP gene was complemented for virus movement in transgenic tobacco expressing the Fny-CMV MP, resulting in a 2day delay in the kinetics of viral RNA accumulation and little to no symptom production. After the initial 2-day delay in viral accumulation, viral RNA was then detected at the same level as wild-type Fny-CMV in wild-type tobacco (Kaplan et al. 1995). In that instance, differences between CMV accumulation in different tissue types were not examined. Nevertheless, it could be hypothesized that, for disease symptoms to develop fully, it is necessary that epidermal cells be adequately infected

Table 2. Numbers of virus-infected epidermal and palisade mesophyll cells $^{\mathrm{a}}$

\begin{tabular}{lccccc}
\hline & \multicolumn{2}{c}{ CMV-GFP } & & \multicolumn{2}{c}{ CMV $\Delta$ 2b } \\
\cline { 2 - 2 } \cline { 5 - 6 } Field & Epidermal & Mesophyll & & Epidermal & Mesophyll \\
\hline Experiment & & & & & \\
1 & 14 & 17 & & 2 & 60 \\
2 & 12 & 12 & & 3 & 50 \\
3 & 12 & 30 & & 2 & 150 \\
4 & 45 & 130 & & 2 & 32 \\
Experiment 2 & & & & \\
1 & 22 & 20 & & 4 & 80 \\
2 & 15 & 20 & & 1 & 13 \\
3 & 11 & 40 & & 4 & 7 \\
\hline
\end{tabular}

${ }^{\mathrm{a}}$ Numbers of cells infected with GFP-tagged CMV or CMV $\triangle 2 \mathrm{~b}$ in fields of view around inoculation sites observed by confocal microscopy. and that predominant infection of mesophyll cells is insufficient. Further investigation into this matter was not possible, because the GFP constructs could not replicate in upper, uninoculated leaves. Therefore, it is unknown what cell types CMV $\triangle 2 \mathrm{~b}$-GFP goes to during systemic delivery of virus to upper leaves. The effect on the ability of the virus to move in different cell types, such as epidermal or mesophyll, may affect the ability of the virus to enter the vasculature. Alternatively,
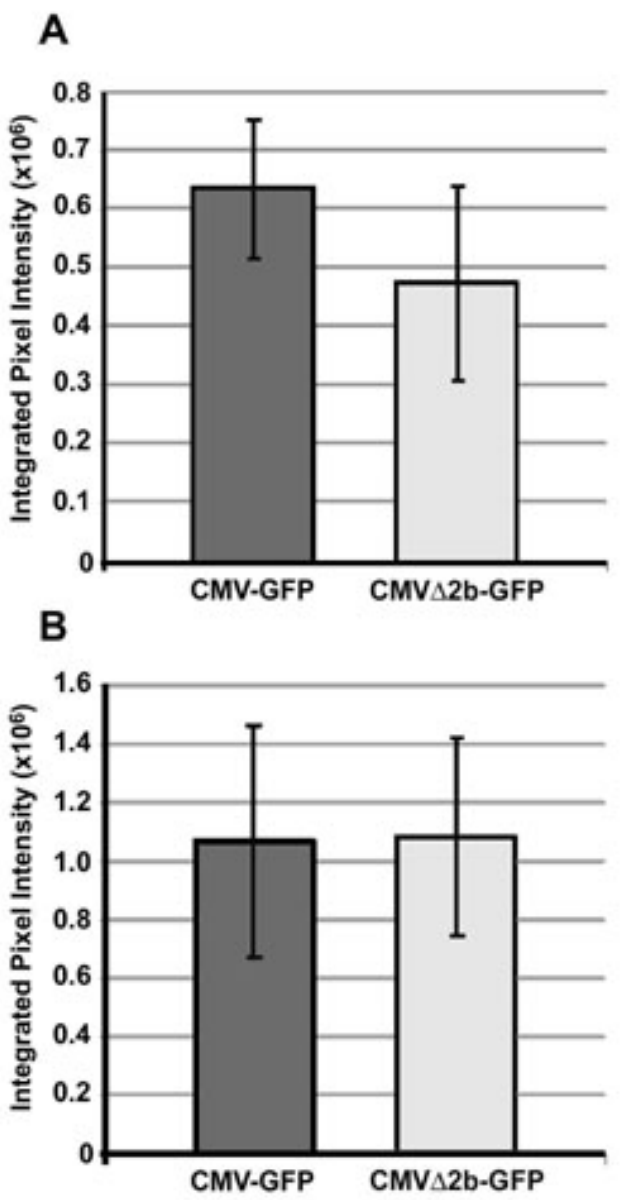

C
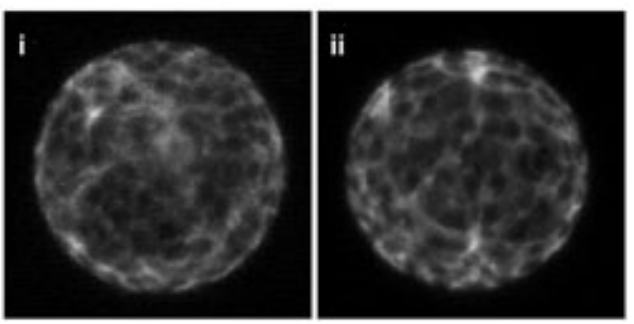

Fig. 5. The accumulation of Cucumber mosaic virus expressing the green fluorescent protein (CMV-GFP) and CMV-GFP with the $2 b$ protein open reading frame deleted (CMV $\Delta 2 \mathrm{~b}-\mathrm{GFP})$ in tobacco protoplasts at $20 \mathrm{~h}$ postinoculation. $\mathbf{A}$ and $\mathbf{B}$, In two independent experiments, GFP fluorescence was used to quantitate the relative amounts of virus replication in protoplasts infected with CMV-GFP or CMV 2 2b-GFP. Each graph bar represents the mean of the integrated (combined) values for pixel intensity for each set of ten protoplast images. Each image was a projection representing total GFP fluorescence from a single protoplast imaged using the confocal laser scanning microscope. The error bars represent the standard deviation about the mean. C, Representative projections of a protoplast infected with CMV-GFP (i) and a protoplast infected with CMV $\triangle 2 \mathrm{~b}-\mathrm{GFP}$ (ii) imaged at $20 \mathrm{~h}$ postelectroporation. Each protoplast was approximately $15 \mu \mathrm{m}$ in diameter. 
the $2 \mathrm{~b}$ protein may affect the ability of the virus to utilize plasmodesmal connections between cells within the vasculature. In either case, we can envisage that the effect on cell-specific movement may, later on in infection, affect the egress of the virus from the vasculature into the upper leaves.

In summary, it is apparent that the $2 b$ protein of Fny-CMV influences the dynamics of movement of the virus through both the inoculated leaf and the whole plant. We propose that the altered movement profile of CMV lacking the $2 \mathrm{~b}$ protein gene is the direct or indirect cause of the decreased severity of disease symptoms seen in tobacco.

\section{MATERIALS AND METHODS}

\section{Viruses, plants, and plasmid constructs.}

Tobacco (Nicotiana tabacum L. cv. Xanthi-nc) was used as the host plant in all of the experiments. Tobacco seeds were sown in a greenhouse maintained at 23 to $27^{\circ} \mathrm{C}$ (using supplementary lighting during the winter, when necessary), and plants were used approximately six weeks after sowing.

The wild-type Fny strain of Cucumber mosaic virus (FnyCMV) (Roossinck and Palukaitis 1990) and various mutants and chimeras used in this study were constructed by mixing transcripts synthesized in vitro as described in Table 1. CMVGFP and CMV $\triangle 2$ b-GFP each contain two modified RNAs 3 (Canto et al. 1997) that encode free GFP (Table 1). These modified RNAs 3 complement each other in that the transcripts encoded by $\mathrm{pF}: \mathrm{GFP} / \mathrm{CP}$ and $\mathrm{pL}: 3 \mathrm{a} / \mathrm{GFP}$ can direct synthesis of the viral coat and movement proteins, respectively (Canto et al. 1997). Fny-CMV $\Delta 2$ b has a modified RNA 2 derived from the plasmid here designated pFny209/M3, in which the sequences encoding the $2 \mathrm{~b}$ protein (nucleotides 2,419 to 2,713 ) have been deleted by site-directed mutagenesis (Ryabov et al. 2001).

Plasmids containing viral sequences were linearized by digestion with PstI and made blunt-ended before use as templates for in vitro transcription in a T7 mMESSAGE mMACHINE kit (Ambion, Austin, TX, U.S.A.). Transcription products were checked by agarose gel electrophoresis. The appropriate transcripts were pooled as shown in Table 1 to make the virus constructs. Ten microlitres of pooled transcripts (total $0.5 \mu \mathrm{g}$ of RNA) were inoculated onto carborundum-dusted leaves.

\section{Detection of CMV proteins in plant tissue.}

Following inoculation or mock inoculation, plants were incubated for a minimum of 2 days, after which one of the inoculated and one of the upper, uninoculated leaves (the youngest leaf at the top of the plant) were harvested, and protein extraction was carried out. Protein extraction and immunoblotting of CMV CP using polyclonal rabbit anti-CMV (strain M) CP was carried out according to Naylor and associates (1998). The extraction and immunoblotting of the $2 \mathrm{~b}$ protein using polyclonal rabbit anti-2b serum was performed as described by Mayers and associates (2000).

\section{Protoplast preparation and infection.}

Protoplasts were prepared from leaves of tobacco plants using previously described methods (Carr and Zaitlin 1991; Hills et al. 1987). Aliquots of protoplasts prepared from the same leaf were inoculated in parallel by electroporation with CMVGFP or CMV $\triangle 2 b-G F P$, using the transcript mixes described in Table 1. Electroporation was performed in a final volume of $0.5 \mathrm{ml}$ sterile $0.7 \mathrm{M}$ mannitol, using a ring electrode $(2.5 \mathrm{~mm}$ high, $1 \mathrm{~cm}$ gap) connected to a ProGenitor II electroporation apparatus (Hoefer Scientific Instruments, San Francisco), by applying two $5 \mathrm{~ms}$ pulses of $300 \mathrm{~V}$. Protoplasts $\left(10^{6}\right)$ were electroporated with an estimated $2.5 \mu \mathrm{g}$ of pooled transcripts. All experiments included a set of mock inoculated protoplasts. Af- ter electroporation, protoplasts were incubated in low light at $25^{\circ} \mathrm{C}$ in wells of sterile polystyrene multiwell plates (Bibby Sterilin Ltd., Stone, U.K.) (Murphy and Carr 2002) coated with $1 \%$ noble agar in incubation medium described in Carr and associates (1994).

\section{Confocal laser scanning imaging.}

Movement of CMV-GFP and CMV $\triangle 2 \mathrm{~b}$-GFP within the epidermis and mesophyll cells of tobacco was observed with a Leica TCS SP confocal laser scanning microscope system using a 10× objective lens. Images were obtained using an argon laser with an excitation wavelength of $488 \mathrm{~nm}$ with a detection wavelength in the range of 505 to $530 \mathrm{~nm}$. Inoculated portions of leaves were sandwiched between two glass slides or a slide and a cover-slip in order to keep the leaf surface as flat as possible. Images were stored on recordable compact disks.

GFP was used as an indicator for replication of CMV and $\mathrm{CMV} \Delta 2 \mathrm{~b}$ in protoplasts. To obtain quantitative data on the accumulation of GFP in protoplasts, the confocal laser scanning microscope system was used to obtain images. Images were taken of CMV-GFP- and CMV $\triangle 2 \mathrm{~b}-\mathrm{GFP}$-infected (fluorescing) protoplasts with all variables set the same for both sets of cells. Note that, in each experiment, the same batch of protoplasts was used for both of the viral constructs. The background (black) was set when the laser was set to scan but the beam was blocked off, and the gain was set to the maximum on the brightest point of the brightest protoplast. The reason for this normalization procedure was to ensure that no fluorescence went undetected by the system. Sixteen evenly spaced optical sections were taken through each of ten protoplasts from each group (infected with CMV-GFP versus CMV $\Delta 2 \mathrm{~b}$ GFP), with two images recorded for each section. These images were stacked to form a projection. 'Metamorph' image analysis software (Universal Imaging Corp., West Chester, NY, U.S.A.) was used to analyze the projections as 8-bit images. For each projection, individual pixel intensity was measured and added together to give an integrated pixel intensity for the projection. The integrated pixel intensity values for the protoplasts infected with the two constructs were compared statistically using Microsoft Excel.

\section{ACKNOWLEDGMENTS}

We thank E. Ryabov for pFny209/M3 and T. Canto for pF:GFP/CP and pL:3a/GFP. We also thank A. Gilliland for useful discussions and statistical advice and S. Hodge and A. Webb for advice on quantitative image analysis. AJS was supported by a studentship from the Biotechnology and Biological Sciences Research Council (BBSRC), AMM by a research fellowship from the Cambridge University Broodbank Fund and a research grant from the Royal Society, and PP by the Scottish Executive Environment and Rural Affairs Department. Work in the laboratory of $\mathrm{J}$. P. C. is supported by grants from the BBSRC and Leverhulme Trust.

\section{LITERATURE CITED}

Adams, M. J., Antoniw, J. F., Barker, H., Jones, A. T., Murant, A. F., and Robinson, D. 1998. Descriptions of Plant Viruses on CD-ROM. Association of Applied Biologists, Wellesbourne, U.K.

Béclin, C., Berthomé, R., Palauqui, J.-C., Tepfer, M., and Vaucheret, H. 1998. Infection of tobacco or Arabidopsis plants by CMV counteracts systemic post-transcriptional silencing of nonviral (trans)genes. Virology 252:313-317.

Brigneti, G., Voinnet, O., Li, L. H., Ding, S. W., and Baulcombe, D. C. 1998. Viral pathogenicity determinants are suppressers of transgene silencing in Nicotiana benthamiana. EMBO (Eur. Mol. Biol. Organ.) J. 17:6739-6746.

Canto, T., Prior, D. A. M., Hellwald, K.-H., Oparka, K. J., and Palukaitis P. 1997. Characterization of cucumber mosaic virus IV. Movement protein and coat protein are both essential for cell-to-cell movement of cucumber mosaic virus. Virology 237:237-248.

Canto, T., and Palukaitis, P. 1999. Are tubules generated by the 3 a protein 
necessary for cucumber mosaic virus movement? Mol. Plant-Microbe Interact. 12:985-993.

Carr, J. P., and Zaitlin, M. 1991. Resistance in transgenic tobacco plants expressing a nonstructural gene sequence of tobacco mosaic virus is a consequence of markedly reduced virus replication. Mol. PlantMicrobe Interact. 4:579-585.

Carr, J. P., Gal-On, A., Palukaitis, P., and Zaitlin, M. 1994. Replicase-mediated resistance to cucumber mosaic virus in transgenic plants involves suppression of both virus replication in the inoculated leaves and long distance movement. Virology 199:439-447.

Carrington, J. C. 1999. Reinventing plant virus movement. Trends Microbiol. 7:312-313

Ding, S. W., Anderson, B. J., Haase, H. R., and Symons, R. H. 1994. New overlapping gene encoded by the cucumber mosaic virus genome. Virology 198:593-601.

Ding, B. A., Li, Q. B., Nguyen, L., Palukaitis, P., and Lucas W. J. 1995a. Cucumber mosaic virus $3 \mathrm{~A}$ protein potentiates cell-to-cell trafficking of CMV RNA in tobacco plants. Virology 207:345-353.

Ding, S. W., Li, W. X., and Symons, R. H. 1995b. A novel naturally occurring hybrid gene encoded by a plant RNA virus facilitates long distance virus movement. EMBO (Eur. Mol. Biol. Organ.) J. 14:5762-5772.

Ding, S. W., Rathjen, J. P., Li, R. S., Swanson, R., Healy, H., and Symons, R. H. 1995c. Efficient infection from cDNA clones of cucumber mosaic cucumovirus RNAs in a new plasmid vector. J. Gen. Virol. 76:459-464

Ding, S. W., Shi, B. J., Li, W. X., and Symons, R. H. 1996. An interspecies hybrid RNA virus is significantly more virulent than either parental virus. Proc. Natl. Acad. Sci. U.S.A. 93:7470-7474.

Hills, G. J., Plaskitt, K. A., Young, N. D., Dunigan, D. D., Watts, J. W. Wilson, T. M. A., and Zaitlin, M. 1987. Immunogold localization of the intracellular sites of structural and nonstructural tobacco mosaic virus proteins. Virology 161:488-496.

Ji, L.-H., and Ding, S.-W. 2001. The suppressor of transgene RNA silencing encoded by Cucumber mosaic virus interferes with salicylic acidmediated virus resistance. Mol. Plant-Microbe Interact. 14:715-724.

Kasschau, K. D., and Carrington, J. C. 2001. Long-distance movement and replication maintenance functions correlate with silencing suppression activity of potyviral HC-Pro. Virology. 285:71-81.

Kaplan, I. B., Shintaku, M. H., Zang, L., Marsh, L. E., and Palukaitis, P. 1995. Complementation of virus movement in transgenic tobacco expressing the cucumber mosaic virus 3A gene. Virology 209:188-199.

Li, W. X, and Ding, S. W. 2001. Viral suppressors of RNA silencing. Curr. Opin. in Biotechnol. 12:150-154.

Lucy, A. P., Guo, H. S., Li, W. X., and Ding, S. W. 2000. Suppression of post-transcriptional gene silencing by a plant viral protein localized in the nucleus. EMBO (Eur. Mol. Biol. Organ.) J. 19:1672-1680.

Mayers, C. N., Palukaitis, P., and Carr, J. P. 2000. Subcellular distribution analysis of the cucumber mosaic virus $2 b$ protein. J. Gen. Virol. 81:219-226.

Murphy, A. M., and Carr, J. P. 2002. Salicylic acid has cell-specific effects on Tobacco mosaic virus replication and cell-to-cell movement. Plant Physiol. 128:552-563.

Naylor, M., Murphy, A. M., Berry, J. O., and Carr, J. P. 1998. Salicylic acid can induce resistance to plant virus movement. Mol. PlantMicrobe Interact. 11:860-868.

Owen, J., and Palukaitis, P. 1988. Characterization of cucumber mosaic virus .I. Molecular heterogeneity mapping of RNA-3 in 8 CMV strains. Virology 166:495-502.

Palukaitis, P., Roossinck, M. J., Dietzgen, R. G., and Franki, R. I. B. 1992. Cucumber mosaic virus. Adv. Virus Res. 41:281-348.

Peden, K. W. C., and Symons, R. H. 1973. Cucumber mosaic virus contains a functionally divided genome. Virology 53:487-492.

Rizzo, T. M., and Palukaitis, P. 1988. Nucleotide sequence and evolutionary relationships of cucumber mosaic virus (CMV) strains - CMV RNA 2. J. Gen. Virol. 69:1777-1787.

Rizzo, T. M., and Palukaitis, P. 1989. Nucleotide sequence and evolutionary relationships of cucumber mosaic virus (CMV) strains RNA-1. J. Gen. Virol. 70:1-11.

Roossinck, M. J., and Palukaitis, P. 1990. Rapid induction and severity of symptoms in zucchini squash (Cucurbita pepo) map to RNA 1 of cucumber mosaic virus. Mol. Plant-Microbe Interact. 3:188-192.

Roossinck, M. J., Zhang, L., and Hellwald, K. H. 1999. Rearrangements in the $5^{\prime}$ nontranslated region and phylogenetic analyses of cucumber mosaic virus RNA 3 indicate radial evolution of three subgroups. J. Virol. 73:6752-6758.

Ryabov, E. V., Fraser, G., Mayo, M. A., Barker, H., and Taliansky, M. 2001. Umbravirus gene expression helps Potato leafroll virus to invade mesophyll tissues and to be transmitted mechanically between plants. Virology 286:363-372.

Shalla, T. A., Peterson, L. J., and Zaitlin, M. 1982. Restricted movement of a temperature-sensitive virus in tobacco leaves is associated with a reduction in numbers of plasmodesmata. J. Gen. Virol. 60:355-358.

Waigmann, E., and Zambryski, P. 1995. Tobacco mosaic virus movement protein mediated protein transport between trichome cells. Plant Cell 7:2069-2079.

Zhang, L., Hanada, K., and Palukaitis, P. 1994. Mapping local and systemic symptom determinants of cucumber mosaic cucumovirus in tobacco. J. Gen. Virol. 75:3185-3191. 